\title{
Endothelial cell-specific activation of transforming growth factor- $\beta$ signaling in mice induces cutaneous, visceral, and microvascular fibrosis
}

\author{
Peter J Wermuth ${ }^{1}$, Kellan R Carney, Fabian A Mendoza², Sonsoles Piera-Velazquez ${ }^{1}$ and Sergio A Jimenez ${ }^{1}$
}

In this study, we tested the hypothesis that constitutive endothelial cell-specific activation of TGF- $\beta$ signaling induces tissue fibrosis and vasculopathy resembling the characteristic fibrotic and vascular alterations of systemic sclerosis. Transgenic mice with inducible expression of a constitutively active TGF- $\beta$ receptor I specifically in endothelial cells were generated by intercrossing mice harboring a constitutively active TGF- $\beta$ receptor I with a mouse strain containing the endothelial cell-specific Cdh5 gene promoter directing the tamoxifen-inducible expression of the Cre-ER ${ }^{\mathrm{T2}}$ cassette. $^{2}$ Administration of tamoxifen to these mice would result in constitutive TGF- $\beta$ activation and signaling confined to endothelial lineage cells. The effects of constitutive TGF- $\beta$ endothelial cell activation were assessed by histopathological examination of skin and various internal organs, tissue hydroxyproline analysis, and assessment of expression of myofibroblast differentiation and TGF- $\beta$ signaling genes employing real-time PCR and immunohistochemical staining of lung vessels for endothelial- and myofibroblast-specific proteins. Constitutive TGF $\beta-1$ signaling in endothelial cells resulted in cutaneous and visceral fibrosis with prominent fibrotic involvement of the lungs and severe perivascular and subendothelial fibrosis of small arterioles. A marked increase in the expression of fibrosis-associated genes and of genes indicative of myofibroblast activation was also found. Confocal microscopy of lung vessels showed evidence consistent with the induction of endothelial-to-mesenchymal transition (EndoMT). Taken together, our data indicate that transgenic mice with constitutive endothelial cell-specific activation of TGF- $\beta$ signaling display severe cutaneous, pulmonary, and microvascular fibrosis resembling the fibrotic and microvascular alterations characteristic of systemic sclerosis.

Laboratory Investigation (2017) 97, 806-818; doi:10.1038/labinvest.2017.23; published online 27 March 2017

Systemic sclerosis (SSc) is a systemic autoimmune disorder characterized by progressive fibrosis of the skin and multiple internal organs accompanied by severe alterations in the microvasculature and cellular and humoral immunity dysfunction. ${ }^{1-3}$ The etiology of SSc is currently unknown and its pathogenesis is quite complex and has not been fully elucidated. ${ }^{4-7}$ However, recent experimental evidence indicates that microvascular damage may represent the initiating stimulus for the subsequent establishment and progression of the fibrotic process. ${ }^{8-14}$ Indeed, it has been suggested that SSc is a vascular disease. ${ }^{13}$ It has been further suggested that the early microvascular-associated damage triggers the perivascular and parenchymal infiltration of the affected tissues with mononuclear immune cells. ${ }^{13-15}$ The infiltrating inflammatory cells release cytokines, growth factors, and other products that subsequently result in the transdifferentiation and activation of various cell types, including quiescent fibroblasts, adipocytes, and endothelial cells, into activated myofibroblasts. ${ }^{16-18}$ Activated myofibroblasts are the cells ultimately responsible for the dysregulated synthesis and exaggerated accumulation of collagen and other fibrotic tissue macromolecules in the skin and the affected visceral organs. ${ }^{19-22}$ Extensive experimental evidence indicates that transforming growth factor- $\beta$ (TGF- $\beta$ ) is a central signaling pathway mediating these events in SSc pathogenesis. ${ }^{23-27}$ Indeed, increased production of TGF- $\beta$ and increased expression of TGF- $\beta$-regulated genes, including the TGF- $\beta$ receptor 1 (TBRI), have been demonstrated in affected tissues from SSc patients. ${ }^{28,29}$ Owing to the strong interest in the role of microvascular endothelial cells in SSc pathogenesis and the

'Jefferson Institute of Molecular Medicine, Thomas Jefferson University, Philadelphia, PA, USA and ${ }^{2}$ Rheumatology Division, Department of Medicine, Thomas Jefferson University, Philadelphia, PA, USA

Correspondence: Dr S Jimenez, MD, Jefferson Institute of Molecular Medicine, Thomas Jefferson University, 233 South 10 th Street, Suite 509 BLSB, Philadelphia,

PA 19107, USA.

E-mail: sergio.jimenez@jefferson.edu

Received 19 September 2016; revised 13 January 2017; accepted 24 January 2017 
suggestions that SSc is a disease mediated by dysfunction of these cells, ${ }^{10-15}$ we recently examined the mechanisms involved in the profibrotic effects of TGF- $\beta$ and endothelin1 in lung microvascular endothelial cells. ${ }^{30}$ The assessment of gene expression levels of TGF- $\beta$ isoforms and of their corresponding receptors in these studies suggested the establishment of a profibrotic autocrine pathway mediated by stimulation of the expression of TGF- $\beta 1$ receptors creating a potent self-stimulating mechanism of activation of TGF- $\beta$ induced EndoMT resulting in strong profibrotic effects. These data allowed to propose a novel mechanism for the development of tissue fibrotic reactions involving the autocrine stimulation of TGF- $\beta$ receptors during TGF- $\beta$ mediated EndoMT. ${ }^{30}$ Thus the major objective of the studies described here was to examine experimentally whether the increased expression of TGF- $\beta$ receptors specifically in cells of the endothelial lineage would result in microvascular and systemic fibrosis resembling the cardinal pathological alterations characteristic of SSc. To test this hypothesis experimentally, we describe here the development of a novel transgenic murine model of tissue fibrosis triggered by the constitutive activation of TGF- $\beta$ signaling specifically in endothelial cells. This animal model would be expected to more closely reproduce the early events of SSc microvascular injury that are postulated to have a crucial role in the development of SSc cutaneous and visceral fibrosis. The novel transgenic mice, designated TBRI ${ }^{\mathrm{Ca}}$-Cdh5-Cre, were obtained by intercrossing the TBRI $^{\mathrm{ca}}$ transgenic mouse strain developed by Sonnylal et al $^{31}$ with a second transgenic strain in which the endothelial lineage-specific Cdh5 gene promoter directs the expression of a Cre-ER ${ }^{\mathrm{T} 2}$ expression cassette specifically in endothelial lineage cells. ${ }^{32,33}$ The Cre-ER ${ }^{\mathrm{T} 2}$ cassette is activated by the administration of 4-OH-tamoxifen resulting in constitutive activation of TGF- $\beta$ signaling confined specifically to cells of endothelial lineage. To confirm that injection of the animals with tamoxifen resulted in the expected expression of the $\mathrm{TBRI}^{\mathrm{CA}}$ transgene in endothelial cells and to verify that no expression occurred in the absence of Cre recombination, we employed immunohistochemistry on skin and lung sections from mock and tamoxifen-injected animals.

The effects of the endothelial cell-specific constitutive activation of TGF- $\beta 1$ signaling were examined by extensive histopathological analysis of the skin and of various internal organs, including the lungs, heart, kidneys, and liver. The extent of collagen accumulation in various tissues was quantitatively assessed employing chemical assays for hydroxyproline and changes in the expression of genes encoding extracellular matrix macromolecules, relevant downstream TGF- $\beta$ transcription factors, and proteins reflecting myofibroblast differentiation and activation were evaluated. Immunofluorescence microscopy was performed to examine whether there was any evidence indicative of EndoMT. We observed that the TBRI ${ }^{\mathrm{ca}}$-Cdh5-Cre mice we generated displayed extensive fibrosis in the skin and in visceral organs most prominently of the lungs. We further observed that these mice displayed severe alterations in the microvasculature resembling the vascular alterations characteristic of human SSc and that these alterations were accompanied by morphological and molecular changes indicative of EndoMT.

\section{MATERIALS AND METHODS \\ Generation of Transgenic Mice with Constitutive Activation of TGF- $\beta$ Signaling Under Control of the Endothelial Cell-Specific Cadherin 5 (Cdh5) Gene Promoter}

All animal studies were reviewed and approved by the Institutional Animal Care and Use Committee at Thomas Jefferson University. The novel $\mathrm{TBRI}^{\mathrm{ca}}$-Cdh5-Cre mouse strain was generated by intercrossing B6Gt(ROSA)26Sor ${ }^{\text {tm } 1}$ $\left(\mathrm{Tgfbr}^{*}\right) \mathrm{Crm}$ mice (a generous gift of Dr Benoit deCrombrugghe) containing a floxed neo-STOP cassette followed by a constitutively active TBRI sequence in the ubiquitously expressed ROSA26 locus ${ }^{31}$ with the $\mathrm{B} 6 \mathrm{Tg}(\mathrm{Cdh} 5$-cre $)$ CIVE23Mlia strain (a generous gift of Dr Luisa Iruela-Arispe) that express the tamoxifen-inducible Cre-ER ${ }^{\mathrm{T} 2}$ expression cassette under the control of the endothelial lineage-specific Cdh5 gene promoter. ${ }^{32,33}$ The resulting TBRI $^{\mathrm{ca}}$-Cdh5-Cre mice were fertile, appeared healthy, and did not show any obvious malformations. To induce the constitutive activation of TBRI signaling in endothelial cells, 8-week-old TBRI ${ }^{\text {ca }}$ Cdh5-Cre mice were injected intraperitoneally (IP) daily with $1 \mathrm{mg}$ 4-OH-tamoxifen for 5 days. Tamoxifen administration was expected to induce the deletion of the floxed neo-STOP cassette and trigger the endothelial lineage cell-specific expression of the constitutively active TBRI allele. A control group comprised four female and six male mice that were mock-injected with corn oil (TBRI ${ }^{\mathrm{ca}}$-Cdh5-Cre control). The experimental group comprised seven female and six male mice that were injected IP with tamoxifen $\left(\mathrm{TBRI}^{\mathrm{ca}}\right.$-Cdh5-Cre+ tamoxifen).

\section{Histopathological Tissue Analysis}

Animals were killed at 8 weeks after the final tamoxifen or corn oil injections followed by excision of full-thickness skin samples from the dorsum of each mouse and isolation of both lungs, both kidneys, and the heart, and liver. A portion of the tissue samples was fixed in 10\% buffered formalin overnight and then stored in $70 \%$ ethanol. Subsequently, the fixed tissues were embedded in paraffin, sectioned ( $5 \mu \mathrm{m}$ thickness) and stained with hematoxylin and eosin or with Masson's trichrome.

Immunohistochemical Analysis of Skin and Lung Tissues Paraffin-embedded sections of the skin and lung from control and tamoxifen-treated animals were deparaffinized and dehydrated following antigen retrieval with a citric acid buffer, as described previously. ${ }^{34}$ Slides were first incubated with blocking IgG solution for $1 \mathrm{~h}$ and then overnight with mouse anti- $\alpha$-smooth muscle actin ( $\alpha$-SMA) antibodies (Abcam; 1:100 dilution) and rabbit anti-von Willebrand 
Table 1 Primers employed for quantitative real-time PCR

\begin{tabular}{|c|c|c|}
\hline Gene & Forward primer $\left(5^{\prime} \rightarrow 3^{\prime}\right)$ & Reverse primer $\left(5^{\prime} \rightarrow 3^{\prime}\right)$ \\
\hline 185 & ACCAGAGCGGAAAGCATTTGCCA & TCGGCATCGTTIATGGTCGGAA \\
\hline Collal & GCATGGCCAAGAAGACATCG & TCCACGTCTCAGCATTGGG \\
\hline Col3al & AGCTITGTGCAAAGTGGAACCTGG & CAAGGTGGCTGCATCCCAATTCAT \\
\hline Comp & GGAGCTGGTGGAGAAGAATATC & AGGAACTGTCTGCTACCTTTG \\
\hline Fn1 & TCCAGGACAACAGCATCAGTGTCA & CCACAGTGGGTTGCAAACCTTCAA \\
\hline$F n-E d a$ & TAAAGGACTGGCATTCACTGA & GTGCAAGGCAACCACACTGAC \\
\hline Mrtfa & CGTGGGCTGGAAGGATAAA & TACTAGCTCAGGACCCTCATAG \\
\hline Snail & TTGTGTCTGCACGACCTGTGGAAA & TCTTCACATCCGAGTGGGTITTGA \\
\hline
\end{tabular}
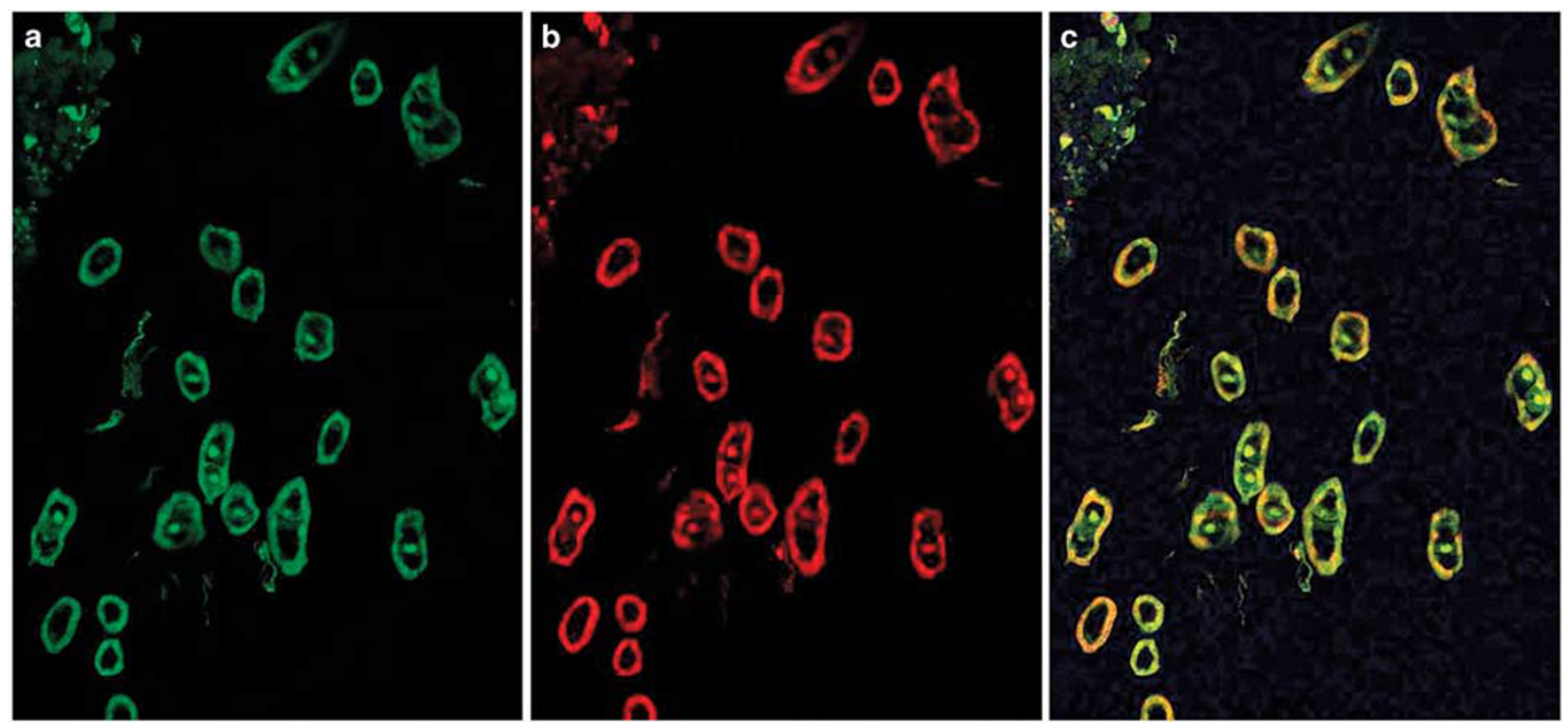

Figure 1 Immunohistology of TBRI ${ }^{\mathrm{ca}}$ transgene expression in the skin isolated from tamoxifen-injected TBRI ${ }^{\mathrm{ca}}$-Cdh5-Cre transgenic mice. Confocal microscopic staining for CD31 (green) and HA (red) in the skin from control transgenic male mice or TGF- $\beta^{\text {ca }} C d h 5$-Cre tamoxifen-injected mice TGF$\beta^{\text {ca } C d h 5-C r e ~(a-c) . ~ D A P I ~ w a s ~ u s e d ~ f o r ~ c o u n t e r s t a i n i n g ~ o f ~ n u c l e i . ~ M a g n i f i c a t i o n: ~} \times 40$. Endothelial cells expressing CD31 (green) are seen lining the large and small vessels of the dermis of both control and tamoxifen-injected animals (a). Cells expressing TBRI ${ }^{\text {ca }}$ (red) are seen only in the vessels of tamoxifen-injected animals (b) but not in vessels in the skin of control mice (not shown). Cells co-staining for CD31 and HA (yellow) are present in the endothelial layer of vessels of the tamoxifen-treated animals (c). No cells co-staining for CD31 and HA were found in the skin from control mice (not shown).

(anti-vWF) antibodies (Dako; 1:50 dilution) or with rabbit anti-hemagglutinin (anti-HA) antibodies (Rockland; 1:100 dilution) and mouse anti-CD31 (Dako; 1:50 dilution) antibodies. IgG binding was revealed following incubation with an $\mathrm{F}\left(\mathrm{ab}^{\prime}\right)$ sheep anti-rabbit $\mathrm{Cy} 3$ antibody and an $\mathrm{F}\left(\mathrm{ab}^{\prime}\right)$ sheep anti-mouse fluorescein isothiocyanate-conjugated antibody (Sigma) for $1 \mathrm{~h}$. Nuclei were counterstained with DAPI (Jackson ImmunoResearch). Samples were examined with a
Zeiss 51 confocal laser microscope to evaluate the colocalization of immunoreactivity.

\section{Determination of Tissue Hydroxyproline Content}

A portion of the skin, lung, kidney, heart, and liver samples isolated from each animal was weighed and acid-hydrolyzed overnight in $6 \mathrm{~N} \mathrm{HCl}$ at $107^{\circ} \mathrm{C}$ and assayed for their total hydroxyproline content as described..$^{35,36}$ The total content of 
a

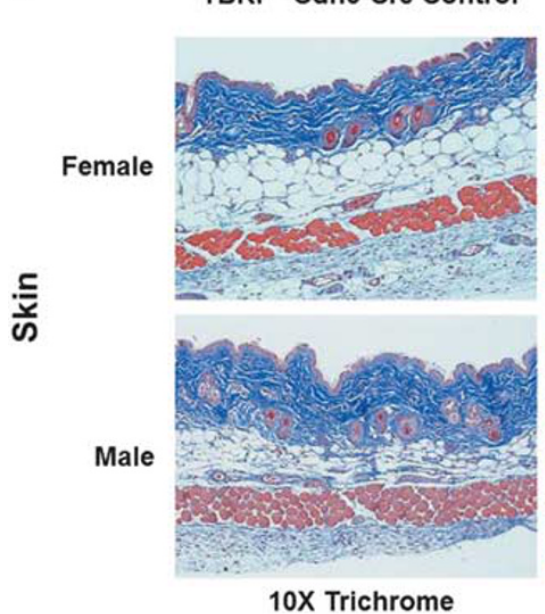

TBRI ${ }^{\text {ca-Cdh5-Cre Control }}$
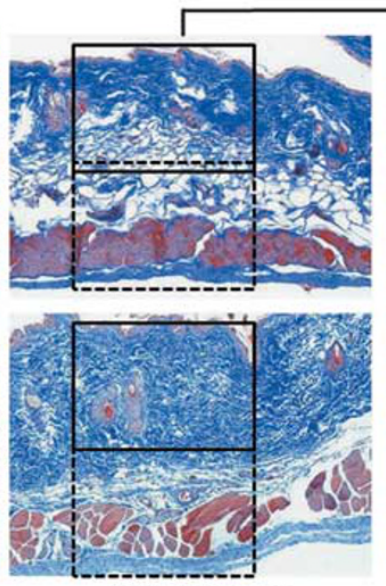

10X Trichrome
TBRIca-Cdh5-Cre+Tamoxifen
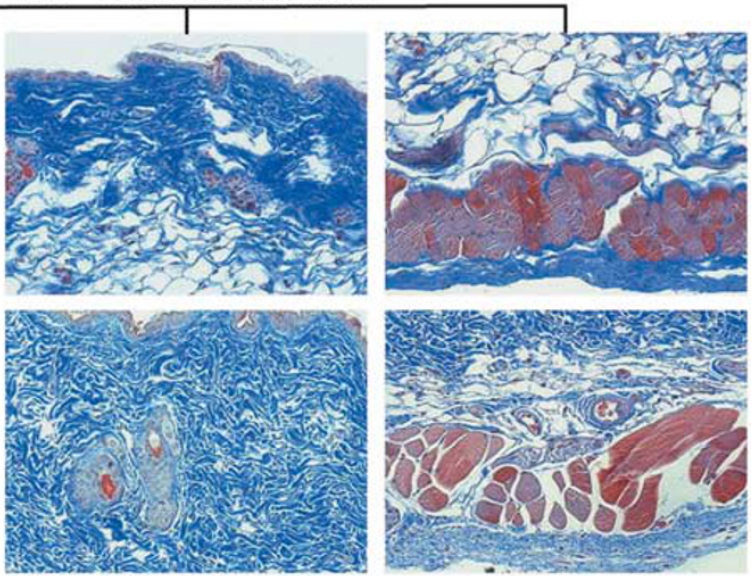

20X Trichrome

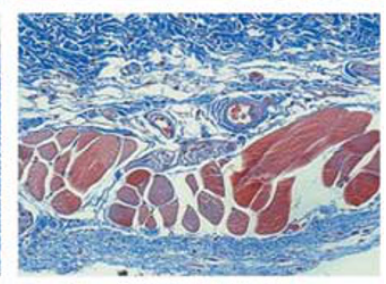

20X Trichrome

b TBRI ca-Cdh5-Cre Control

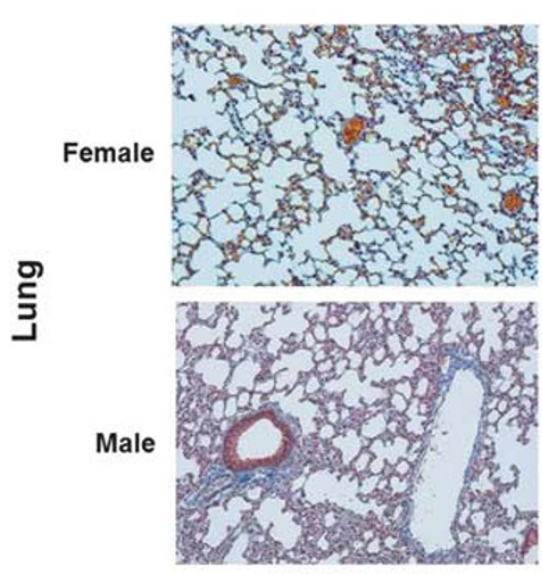

10X Trichrome

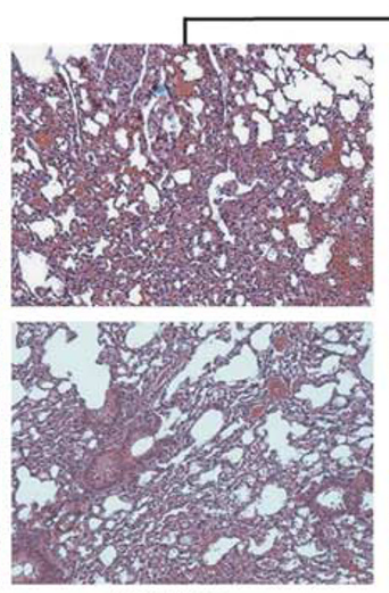

10X H\&E

TBRI ca-Cdh5-Cre+Tamoxifen

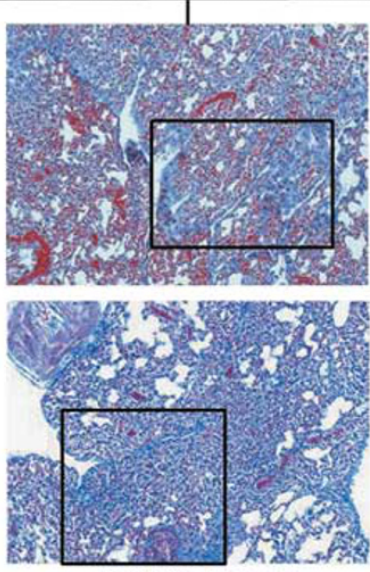

10X Trichrome

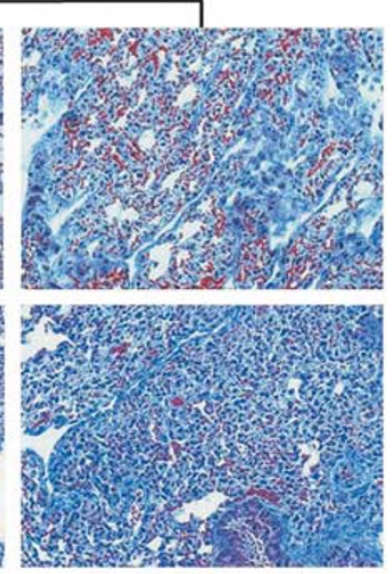

20X Trichrome

Figure 2 Histopathology of skin and lung from control and tamoxifen-injected TBRI ${ }^{\text {ca }}$-Cdh5-Cre transgenic mice. (a) Skin. Skin sections from corn oilinjected control mice. Note normal dermal thickness and normal subdermal adipose tissue layer, panniculum carnosus, and subdermal fascia. There is no accumulation of perivascular fibrous tissue in the deep subdermal region (magnification $\times 10$, left panel). Skin sections from tamoxifen-injected TBRI $^{\text {ca }}$-Cdh5-Cre mice demonstrate increased dermal thickness and perivascular collagen accumulation (magnification $\times 10$, center left panel and magnification $\times 20$, two right panels). The solid box in the center left panel indicates the region of magnification for the center right panel and the dashed box indicates the region of magnification for the far right panel. (b) Lung. Sections from the lung from control mice (left panel magnification $\times 10$, trichrome stain). Sections from TBRI ${ }^{\text {ca }}$-Cdh5-Cre tamoxifen-injected mice (magnification $\times 10$, hematoxylin-eosin stain, center left panel and trichrome strain, center right panel and magnification $\times 20$, trichrome stain, right panel). Note marked loss of alveolar morphology with tissue consolidation and thickening of alveolar septae in hematoxylin-eosin-stained sections (center left panel) and perivascular and interstitial collagen accumulation in trichrome-stained sections (center and right panels). The solid box in the center left panel indicates the region of magnification for the center right panel.

hydroxyproline in the hydrolyzed samples was determined from a standard curve prepared by dissolving hydroxyproline in distilled $\mathrm{H}_{2} \mathrm{O}$ and was expressed as $\mu \mathrm{g}$ hydroxyproline per $\mathrm{mg}$ of wet tissue weight.

\section{RNA Isolation and Real-Time PCR}

Total RNA was extracted from a portion of skin and lung samples using Trizol and was reverse transcribed using SuperScript II Reverse Transcriptase (Invitrogen) to generate first-strand cDNA. Transcript levels of genes associated with fibrosis, with myofibroblast differentiation and activation, and of genes encoding downstream TGF- $\beta$ transcription factors were determined using SYBR Green real-time PCR as previously described. ${ }^{37,38}$ Primers were designed using Primer Quest (Integrated DNA Technologies) and were validated for specificity. The sequence of the primers employed is shown in Table 1 . The differences in the number of mRNA copies in each PCR were corrected for $18 \mathrm{~S}$ RNA endogenous control transcript levels; expression levels in female control mice were set at $100 \%$ and all other values were expressed as normalized multiples of the female control values. 


\section{Statistical Analysis}

Values reflect the mean \pm s.d. from the skin or lung isolated from four female and three male corn oil-injected controls and seven female and six male tamoxifen-injected animals performed in triplicate. The statistical significance of all the data was assessed by a two-tailed Student's $T$-test. A $P<0.05$ was considered statistically significant.

\section{RESULTS}

\section{Generation of TBRI ${ }^{\mathrm{ca}}$-Cdh5-Cre Mice with Tamoxifen- Inducible Constitutive TGF- $\beta$ Signaling in Endothelial Cells}

To determine the effect of constitutive TGF- $\beta$ signaling in cells of the endothelial lineage, we generated a novel transgenic line, denoted $\mathrm{TBRI}^{\mathrm{ca}}$-Cdh5-Cre, by intercrossing transgenic mice with constitutive TGF- $\beta$ signaling in fibroblastic cells (TBRI ${ }^{\mathrm{ca}}$ mice) described by Sonnylal et $a b^{31}$ with the B6 $\mathrm{Tg}$ (Cdh5-cre)CIVE23Mlia strain. ${ }^{32,33}$ Tamoxifen treatment of TBRI ${ }^{\mathrm{ca}}$-Cdh5-Cre progeny generated from this intercross activated the constitutive signaling of TGF- $\beta$ in endothelial cells and allowed to examine the histopathological, biochemical, and molecular effects of endothelial lineagespecific TGF- $\beta$ constitutive signaling activation.

\section{TBRI $^{\text {ca }}{ }^{\text {Expression in Tamoxifen-Injected TBRI }}{ }^{\mathrm{ca}}$-Cdh5-Cre Mice}

To assess whether injection of the animals with tamoxifen induced the expression of the constitutively active TBRI gene and to verify that no expression occurred in the absence of Cre recombination, we examined skin and lung sections from mock and tamoxifen-injected animals employing confocal microscopy. Endothelial cells were identified utilizing anti-CD31 antibody (Figure 1a) and the expression of the TBRI $^{\text {ca }}$ allele was detected using an antibody directed against

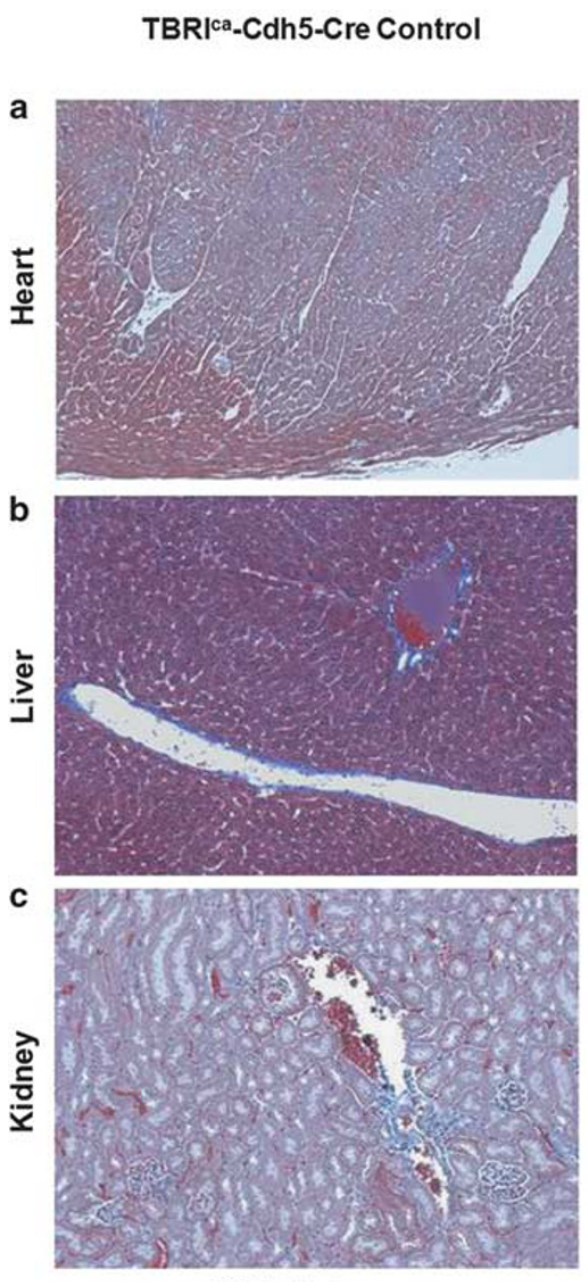

10X Trichrome
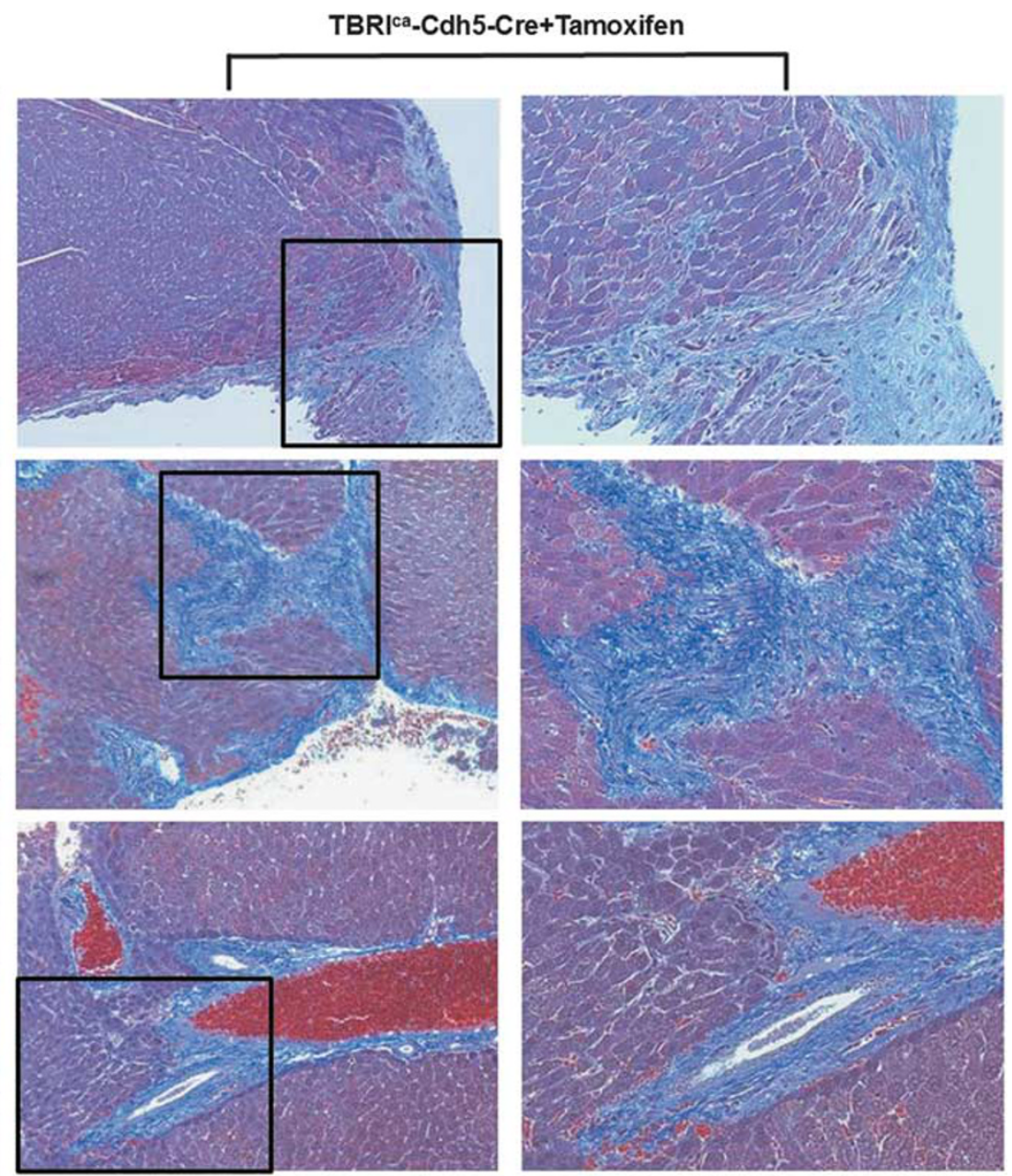

10X Trichrome

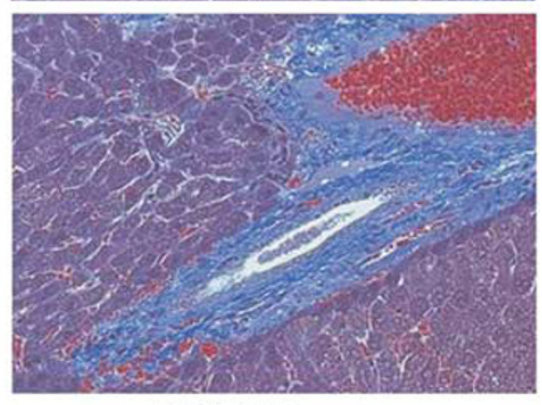

20X Trichrome

Figure 3 Histopathology of the kidney, heart, and liver from control and tamoxifen-injected TBRI ${ }^{\text {ca }}$-Cdh5-Cre transgenic mice stained with Masson's trichrome. Sections from the heart (a), liver (b), and kidney (c) from control mice (magnification $\times 10$, left panel). Sections from TBRI ${ }^{\text {ca }}$ Cdh5-Cretamoxifen-injected mice (magnification $\times 10$, center panel and magnification $\times 20$, right panel). The solid box in the center panel indicates the region of magnification for the right panel. 
the hemagglutinin tag sequence (anti-HA) encoded in the transgene (Figure $1 \mathrm{~b}$ ). We observed intense staining of blood vessels with the anti-HA antibody in the tamoxifen-treated animals (red staining, Figure 1b), whereas only faint background staining was observed in mock-injected animals (not shown). Merging the signals confirmed the coexpression of CD31 and TBRI I ${ }^{\mathrm{ca}}$ in the vessels of the dermis in tamixofeninjected animals (yellow, Figure 1c) in contrast to the lack of colocalized staining in the mock-injected vessels (not shown). Although we did not perform a quantitative assessment of the recombination efficiency of the TBRI transgene, it is apparent from a comparison of Figure 1a with Figure $1 \mathrm{~b}$ that endothelial cells in essentially all vessels present in the tissue (identified with green fluorescence) contained the transgene as all were also stained with the antibody to the tagged HA (identified with red fluorescence).

\section{Dermal Fibrosis Induced by Endothelial-Specific Constitutive TGF- $\beta$ Signaling in Tamoxifen-Injected TBRI $^{\text {ca }}$-Cdh5-Cre Mice}

Histopathological analysis of hematoxylin/eosin-stained fullthickness skin sections from TBRI ${ }^{\mathrm{ca}}$-Cdh5-Cre tamoxifeninjected mice demonstrated a marked increase in dermal thickness, with striking accumulation of densely packed and irregularly arranged collagen bundles throughout the upper and lower dermis and replacement of subcutaneous adipose tissue by compact connective tissue (not shown). Sections stained with trichrome confirmed the increased dermal and subdermal thickening and displayed a marked accumulation of blue staining extracellular matrix collagen in the dermal and subdermal layer of the skin in the tamoxifen-injected animals compared with the control mice (Figure 2a). The hypodermis also showed marked collagen infiltration as well a

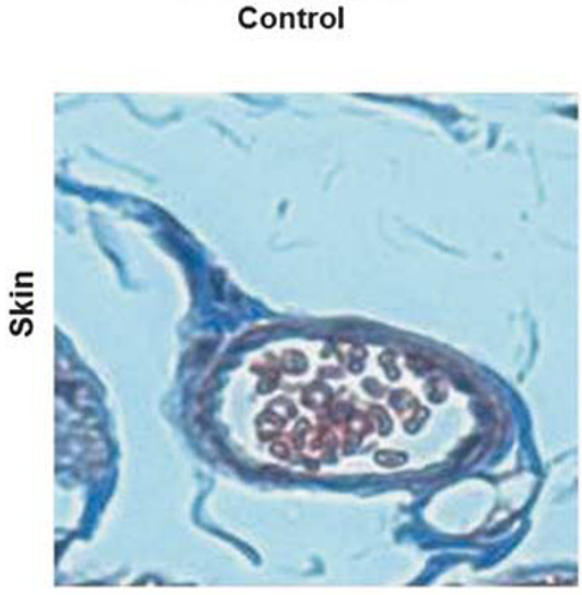

b

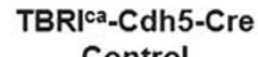

Control

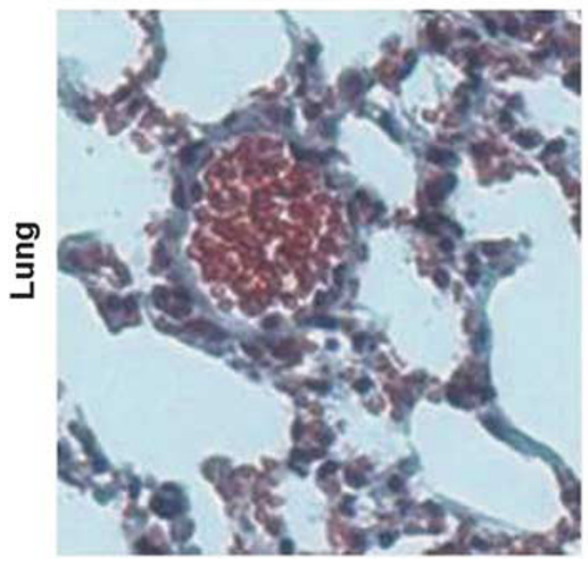

TBRIca-Cdh5-Cre +Tamoxifen
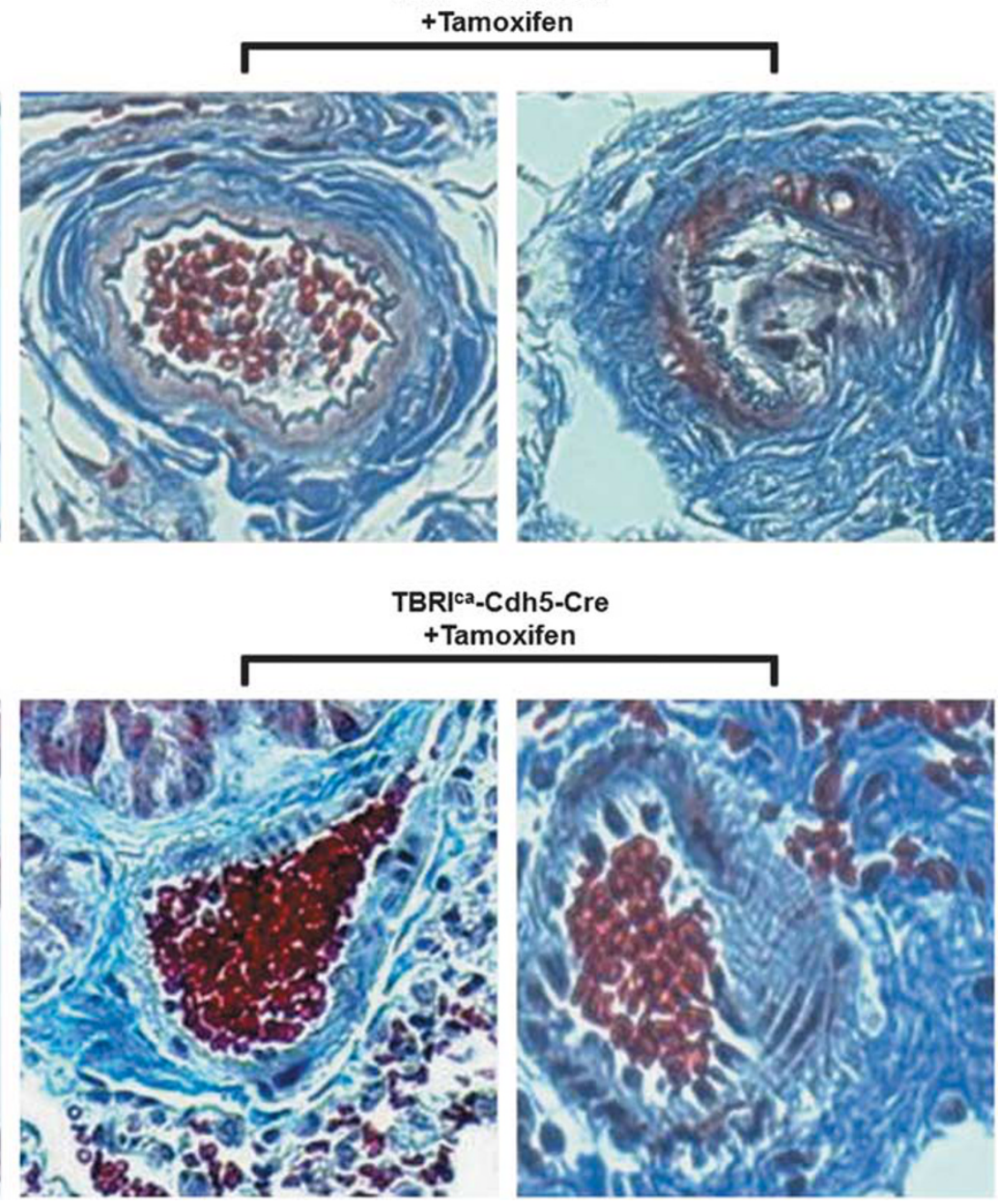

Figure 4 Histopathology of the skin and lung microvasculature in TBRI ${ }^{\text {ca }}$-Cdh5-Cre transgenic mice. Skin sections (a) and lung sections (b) from control mice (left panel) and from TBRI ${ }^{\mathrm{ca}}$-Cdh5-Cre-tamoxifen-injected mice (two right panels). Note extensive collagen accumulation in the subendothelial space and surrounding vessels as well as marked narrowing with almost complete obliteration of vascular lumen by intensely staining collagen fibrotic tissue (magnification $\times 20$ ). 

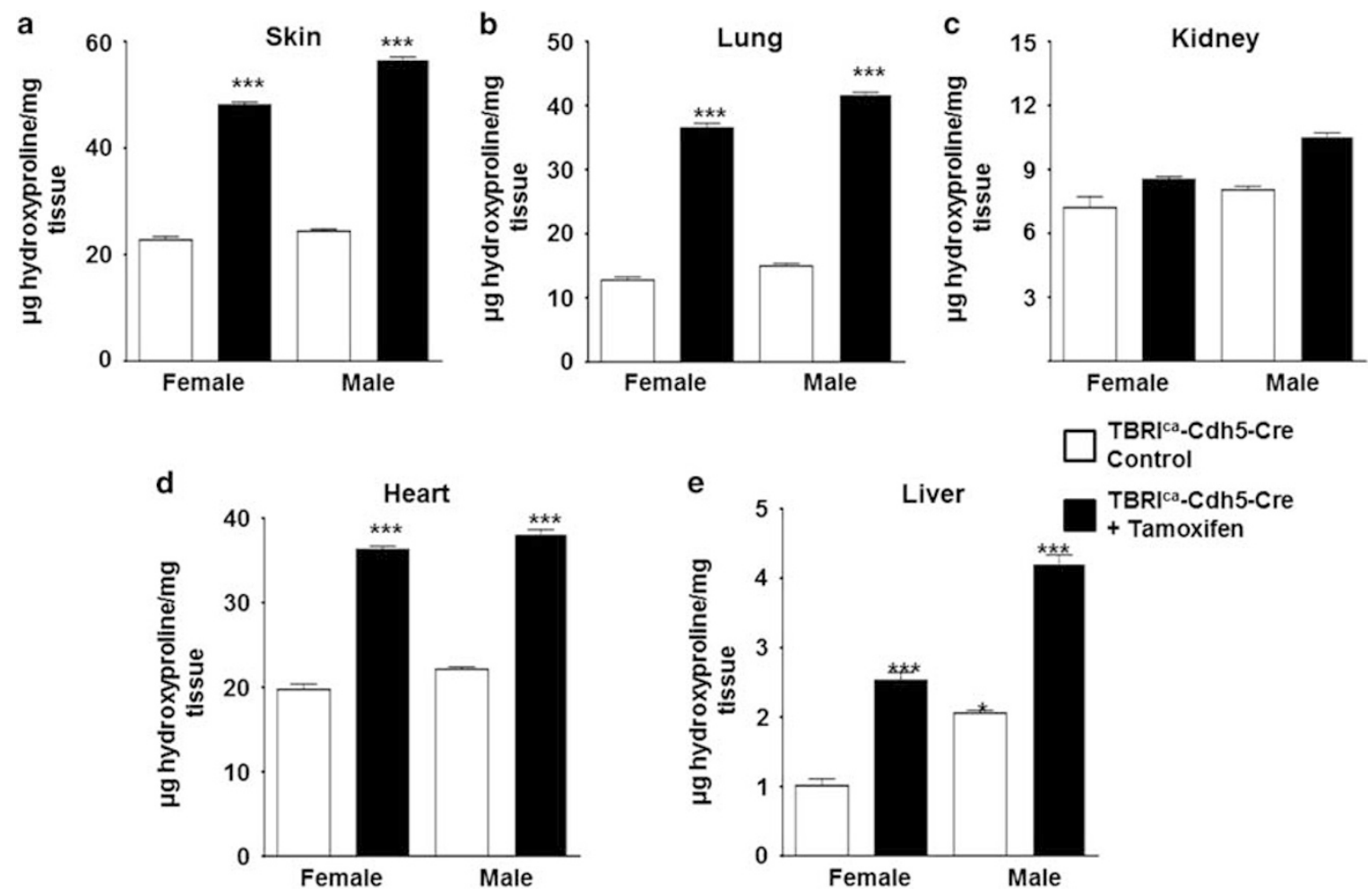

Figure 5 Hydroxyproline content of tissues from control and tamoxifen-injected TBRI ${ }^{\text {ca }}$-Cdh5-Cre mice. A portion of skin (a), lung (b), kidney (c), heart (d), or liver (e) sections isolated from each treatment group of control females $(N=4)$, tamoxifen-injected females $(N=7)$, control males $(N=3)$, or tamoxifen-injected males $(N=6)$ were hydrolyzed and analyzed for hydroxyproline content $(\mu \mathrm{g} / \mathrm{mg}$ of tissue wet weight). The bars show the mean \pm s.d. of each treatment group performed in triplicate. Significance determined by Student's two-tailed $T$-test. ${ }^{*} P<0.05,{ }^{*} P<0.01,{ }^{* * *} P<0.001$.

as a decrease in the overall thickness of the adipose layer. Collagen infiltration was also detected in between individual muscle fibers of the panniculus carnosus. Both male and female tamoxifen-injected animals displayed striking and extensive fibrosis, although male mice displayed greater fibrotic alterations compared with females (Figure 2a). The epidermis did not display evident differences between the control and tamoxifen-activated groups.

\section{Pulmonary Fibrosis in Tamoxifen-Injected TBRI ${ }^{\text {ca }}-$ Cdh5- Cre Mice}

Hematoxylin/eosin staining of the lungs from tamoxifeninjected animals displayed severe alterations of the normal alveolar architecture with extensive areas of fibrosis causing thickening of the alveolar septae and parenchymal consolidation, compared with the lungs isolated from corn oil-injected control mice (Figure 2b). In trichrome-stained sections, marked accumulation of collagen was present in the interstitium and most vessels and peribronchiolar regions displayed increased collagen deposition (Figure 2b). Whereas increased collagen deposition was present in the lungs of tamoxifen-injected animals from both sexes, the lungs of male tamoxifen-injected mice displayed a greater increase in interstitial collagen accumulation compared with tamixofeninjected female animals (Figure $2 b$ ).

\section{Tamoxifen-Injected TBRI ${ }^{\mathrm{Ca}}$-Cdh5-Cre Mice Display Marked Visceral Fibrosis}

In addition to the fibrosis observed in the skin and lungs of tamoxifen-injected animals, increased collagen deposition and fibrosis predominantly with perivascular localization were observed in the kidneys, heart, and liver (Figure 3). Besides the vascular and perivascular fibrosis observed in all these tissues in tamoxifen-injected animals, collagen infiltration in the pericardium was a notable manifestation of fibrosis. Also, some areas of interstitial peritubular fibrosis were noted in the kidneys and severe periportal fibrosis was observed in the liver (Figure 3).

\section{Microvascular Fibrosis in the Skin and Lungs of Tamoxifen-Injected TBRI ${ }^{\text {ca }}$-Cdh5-Cre Mice}

A striking accumulation of collagen was observed surrounding most blood vessels in the deeper layers of the skin and in the microvasculature of the lungs of tamoxifen-treated animals (Figure 4). Numerous small vessels in the skin and lungs of tamoxifen-injected mice also displayed subendothelial accumulation of fibrotic tissue resulting in narrowing of the vessel lumen (Figure 4). Although these changes were more pronounced in male animals, the tissues of female tamoxifen-injected mice also revealed similar vascular alterations (not shown). In the kidneys, abnormal collagen 
a

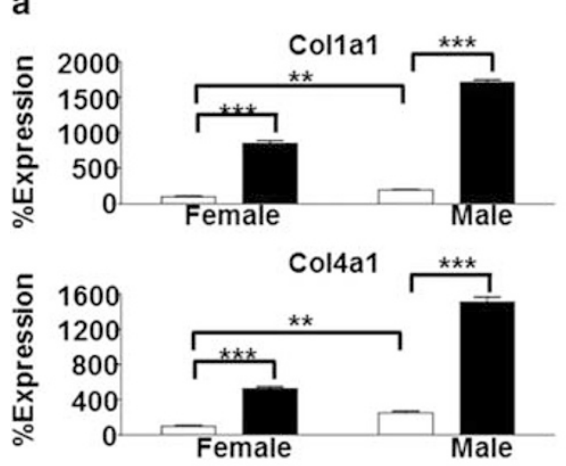

b

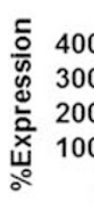

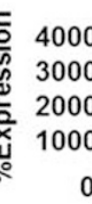

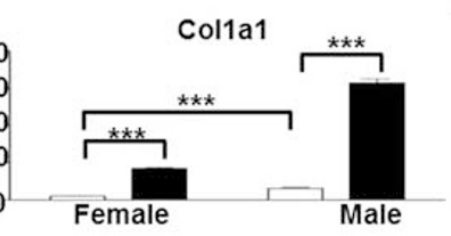

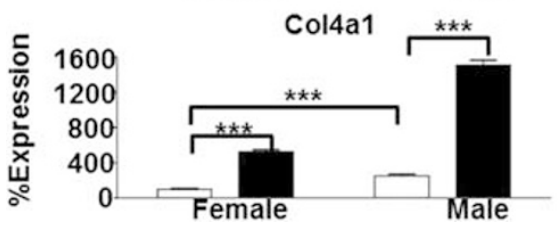

Skin

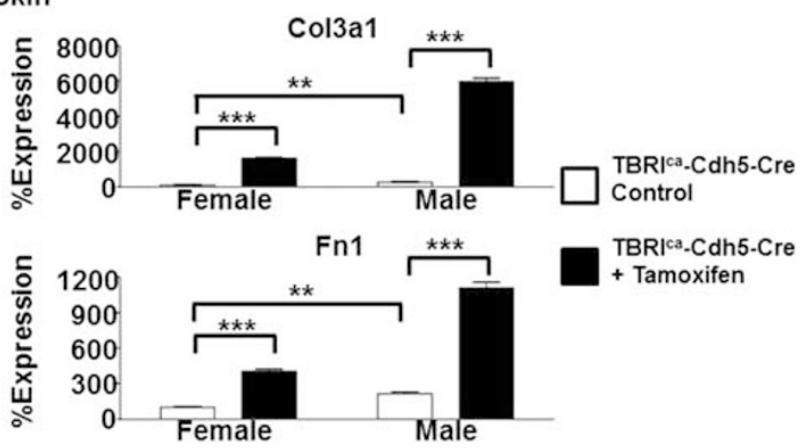

Lung

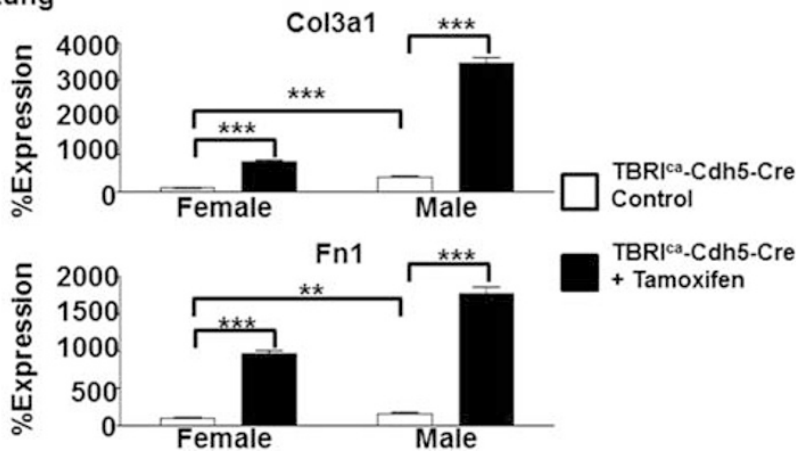

Figure 6 Expression of genes encoding extracellular matrix components in the skin and lungs of control and tamoxifen-injected TBRI ${ }^{\text {ca }}$-Cdh5-Cre transgenic mice. Expression of Col1a1, Col3a1, Col4a1, and Fn from the skin (a) and lung (b). The values shown are the mean ( \pm s.d.) fold change levels of gene expression from each treatment group of control females $(N=4)$, tamoxifen-injected females $(N=7)$, control males $(N=3)$, or tamoxifen-injected males $(N=6)$ performed in triplicate for each tissue. Expression levels were normalized to $18 \mathrm{~S}$ levels and the expression levels in corn oil-injected control female animals were arbitrarily set at the $100 \%$ expression level. Values for other samples are expressed relative to this control. Significance was determined by Student's $T$-test. Statistical significance: ${ }^{*} P<0.05,{ }^{* *} P<0.01,{ }^{* * *} P<0.001$.

deposition occurred surrounding blood vessels and arterioles, and extensive collagen deposition was also noted surrounding the vessels in the liver of tamoxifen-injected animals compared with the control animals (Figure 3).

\section{Hydroxyproline Content of Tissues of Tamoxifen- Injected TBRI ${ }^{\text {ca }}$-Cdh5-Cre Mice}

Samples of the skin, lungs, kidneys, heart, and liver obtained from control and tamoxifen-injected $\mathrm{TBRI}^{\mathrm{ca}}$-Cdh5-Cre mice were assayed for hydroxyproline content to assess quantitatively the extent of collagen deposition in these tissues. The results are shown in Figure 5. Skin samples from tamoxifeninjected mice contained approximately greater than twofold more hydroxyproline than control animals and the lungs from tamoxifen-injected mice had nearly threefold more hydroxyproline than control mice. The hydroxyproline content of the hearts and livers from tamoxifen-injected animals was approximately twofold higher than those of control mice. A slight increase in hydroxyproline content was measured in the kidneys following tamoxifen activation of TGF- $\beta$ signaling but this did not achieve statistical significance.

\section{Increased Expression of Extracellular Matrix Genes Associated with Fibrosis in the Tamoxifen-Injected TBRI $^{\text {ca }}$-Cdh5-Cre Skin and Lungs}

Changes in the expression levels of relevant extracellular matrix genes in the skin and lungs of animals with constitutive endothelial cell TGF- $\beta$ signaling following tamoxifen injection compared with control mice were measured by quantitative RT-PCR of reverse-transcribed total RNA and are shown in Figure 6. Expression levels of the genes for fibrillar collagens Colla1 and Col3a1 were upregulated by an average of 8.5- and 16.1 fold, respectively, in the skin of female mice and 8.8- and 21.7-fold, respectively, in the skin from male mice. The Colla1 and Col3a1 genes expression levels were, respectively, 8.4- and 8.0-fold greater in the lungs of female mice and 10.1- and 8.7-fold in the lungs of male mice. Col4a1 gene expression was increased by 5.3 -fold in the skin and 4.3-fold in the lungs of female mice and 6.0-fold in the skin and 5.1-fold in the lungs of male mice. Total Fn1 gene expression was increased 4.0-fold in skin and 9.6-fold in the lungs in female tamoxifen-injected animals and was 5.2-fold greater in the skin and 11.0-fold greater in the lungs of male tamoxifen-injected animals. 

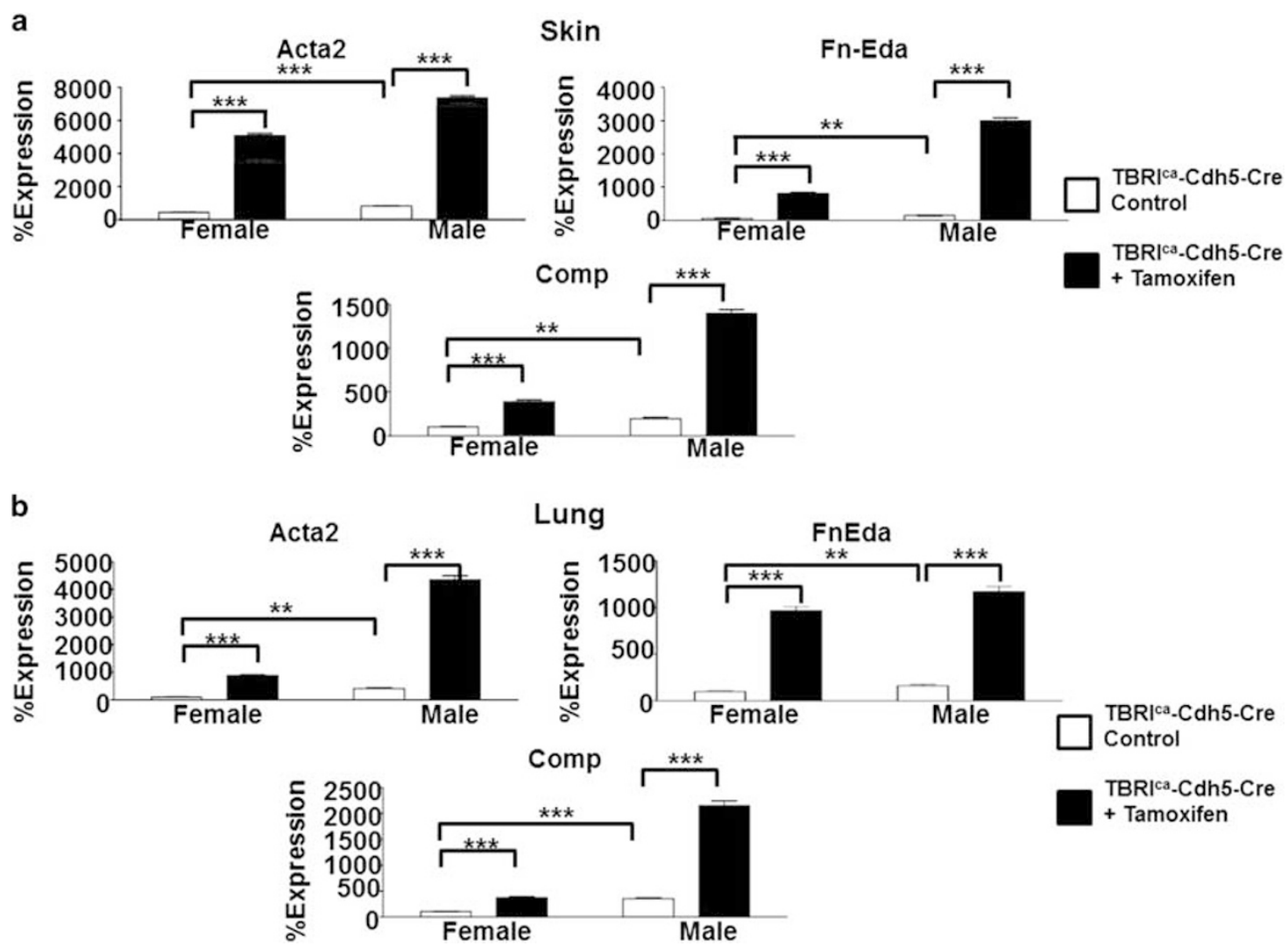

Figure 7 Expression of genes associated with myofibroblast differentiation in the skin and lungs of control and tamoxifen-injected TBR ${ }^{\mathrm{ca}}$-Cdh5-Cre transgenic mice. Expression of Acta2, Fn-Eda, and Comp from the skin (a) and lung (b). The values shown are the mean ( \pm s.d.) fold change levels of gene expression from each treatment group of control females $(N=4)$, tamoxifen-injected females $(N=7)$, control males $(N=3)$, or tamoxifen-injected males $(N=6)$ performed in triplicate for each tissue. Expression levels were normalized to 185 levels and the expression levels in control female animals were arbitrarily set at the $100 \%$ expression level. Values for other samples are expressed relative to this control. Significance was determined by Student's $T$-test. Statistical significance: ${ }^{*} P<0.05,{ }^{* *} P<0.01$, ${ }^{* *} P<0.001$.

\section{Increased Expression of TGF- $\beta$ Target Transcription Factors in the Tamoxifen-Injected TBRI ${ }^{\mathrm{ca}}$-Cdh5-Cre Skin and Lungs}

The expression levels of genes encoding various transcription factors considered to be TGF- $\beta$ targets and to have crucial roles in the EndoMT process were consistently and strongly upregulated in the skin and lungs of animals with constitutive endothelial cell TGF- $\beta$ signaling (Figure 7). The transcription factor Snail was expressed an average of 5.1-fold higher in females and 6.9-fold higher in males in the skin and 3.7-fold higher in females and 4.6-fold higher in males in the lungs of tamoxifen-injected mice, whereas Snai2 expression was upregulated an average of 3.8-fold in females and 4.6-fold in males in the skin and 4.6-fold in females and 6.1-fold in males in the lungs. Twist expression was upregulated 2.8-fold in the skin of females and 3.1-fold in the skin of males and was 2.8-fold higher in females and 5.4-fold higher in males in the lungs. Mrtfa expression was increased 5.3-fold in females and 6.1-fold in males in the skin and 5.9-fold in females and 6.4-fold in males in the lungs of tamoxifen-injected animals.

\section{Increased Expression of Genes Associated with Myofibroblast Differentiation in the Skin and Lungs of Tamoxifen-Injected TGF- $\beta$-Cdh5-Cre Mice}

The expression of genes associated with the transdifferentiation of fibroblasts to activated myofibroblasts was also markedly increased in the skin and the lungs (Figure 8) of mice with tamoxifen-induced constitutive TGF- $\beta$ signaling. The expression levels of Acta2, the gene encoding $\alpha$-SMA, were increased an average of 12.7 -fold in females and 18.9-fold in males in the skin and 8.7-fold in females and 10.4-fold in males in the lungs of animals with constitutive TGF- $\beta$ signaling. Comp expression was increased an average of 3.9-fold in females and 7.2-fold in males in the skin and 3.7-fold in females and 6.1-fold in males in the lungs of tamoxifen-injected mice and the $F n$-Eda splice variant was expressed 10.1-fold higher in females and 19.7-fold higher in males in the skin and 4.7-fold higher in females and 5.1-fold higher in males in the lungs of tamoxifen-injected mice compared with control mice. 
a

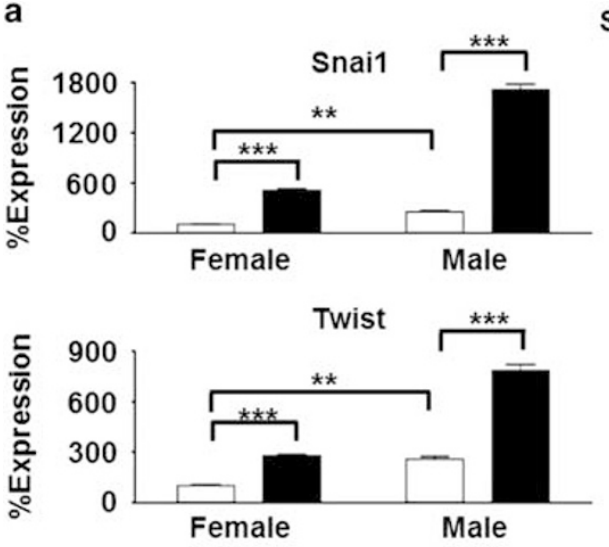

b
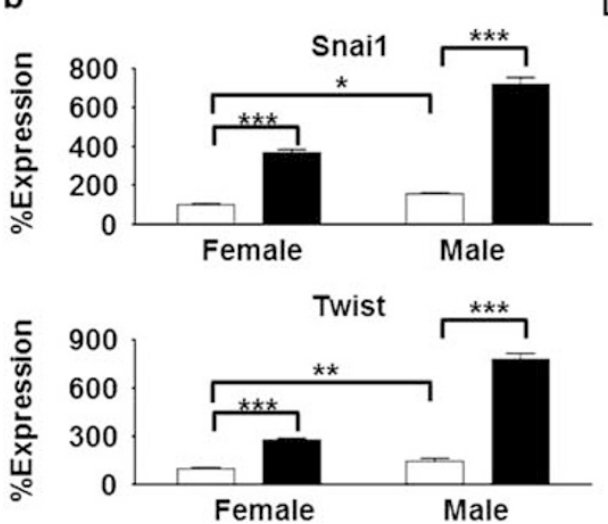

Skin
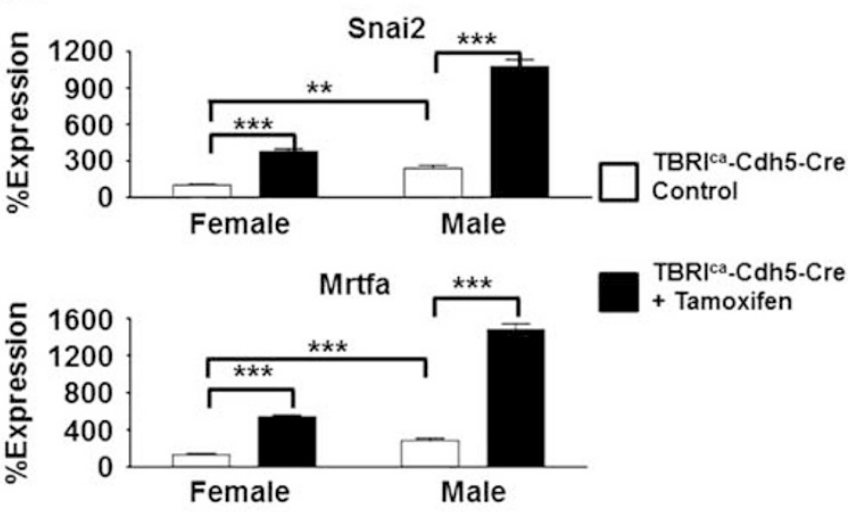

Lung

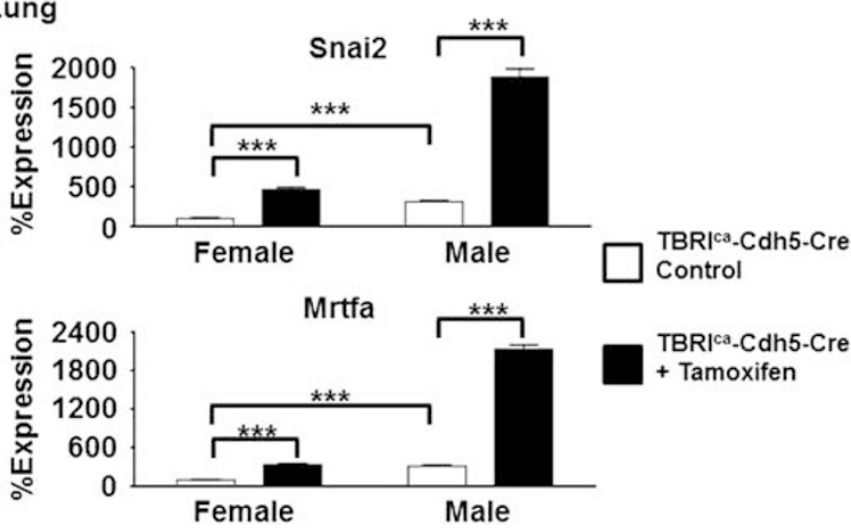

Figure 8 Expression of genes encoding profibrotic TGF- $\beta$-regulated transcription factors in the skin and lungs of control and tamoxifen-injected TBRI ${ }^{\text {ca }}$ Cdh5-Cre transgenic mice. Expression of Snai1, Snai2, Twist, and Mrtfa from the skin (a) and lung (b). The values shown are the mean ( \pm s.d.) fold change levels of gene expression from each treatment group of control females $(N=4)$, tamoxifen-injected females $(N=7)$, control males $(N=3)$, or tamoxifen-injected males $(N=6)$ performed in triplicate for each tissue. Expression levels were normalized to $18 \mathrm{~S}$ levels and the expression levels in control female animals were arbitrarily set at the $100 \%$ expression level. Values for other samples are expressed relative to this control. Significance was determined by Student's $T$-test. Statistical significance: ${ }^{*} P<0.05$, ${ }^{* *} P<0.01,{ }^{* * *} P<0.001$.

Increased $a$-SMA-Positive Myofibroblasts in the Lungs of TBRI $^{\text {ca }}$-Cdh5-Cre Mice with Tamoxifen-Induced

\section{Constitutive TGF- $\boldsymbol{\beta}$ Expression}

Immunofluorescence staining of paraffin-embedded sections of lung of control mice for $\alpha$-SMA and vWF showed a clear separation in the expression of each of these proteins in the tissue with vWF staining confined to the vascular endothelial cell layer and the $\alpha$-SMA staining confined to subendothelial/ medial smooth muscle cells, with no detectable overlap of expression (Figures 9a and c). In contrast, in tamoxifeninjected mice, there was an increase in the number of $\alpha$-SMApositive cells, particularly in the subendothelial region and surrounding the vasculature of the small vessels, and numerous vWF-positive cells simultaneously displayed the expression of $\alpha$-SMA (Figures $9 \mathrm{~b}$ and $\mathrm{d}$ ).

\section{DISCUSSION}

We report here studies demonstrating that tamoxifeninduced endothelial-specific constitutive TGF- $\beta$ signaling in the TBRI $^{\text {ca }}$-Cdh5-Cre mouse strain we generated induces tissue fibrosis in the skin, lungs myocardium, pericardium, liver and kidneys accompanied by severe fibroproliferative vasculopathy most prominent in the microvasculature. Histopathological analysis of the skin demonstrated marked thickening of the dermis with increased deposition of thickened and disorganized collagen fibers in the upper and lower dermis and replacement of the hypodermal fat layer and the underlying muscle tissue with collagen (Figure 2a) in tamoxifen-treated animals compared with control mice. Similarly, there was a marked increase in collagen deposition in the visceral organs examined. Most striking was the marked fibrotic changes in the lung interstitium with profound alterations in the normal tissue architecture (Figure 2b). Increased collagen deposition was also noted in the heart, liver, and kidneys (Figure 3). A remarkable observation was the marked subendothelial and perivascular accumulation of abundant fibrotic tissue in the vessels of the skin and the lungs of tamoxifen-treated mice causing narrowing of vessel lumen (Figure 4).

Consistent with the histopathological analysis, increased levels of collagen deposition were confirmed by assessment of hydroxyproline content in these tissues from tamoxifen- 
TBRI ${ }^{\mathrm{ca}}{ }_{-}$Cdh5-Cre Control
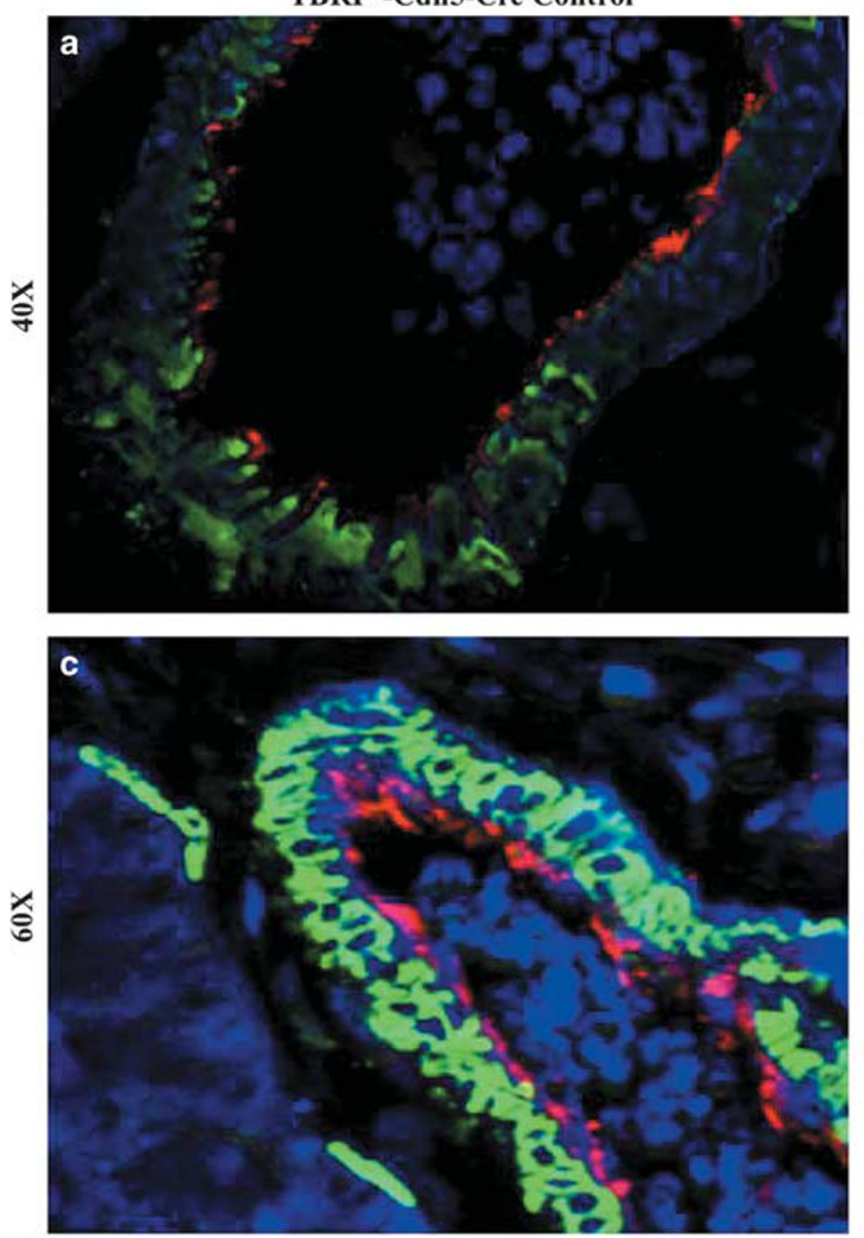

TBRI ${ }^{\text {ca }}$ Cdh5-Cre+Tamoxifen
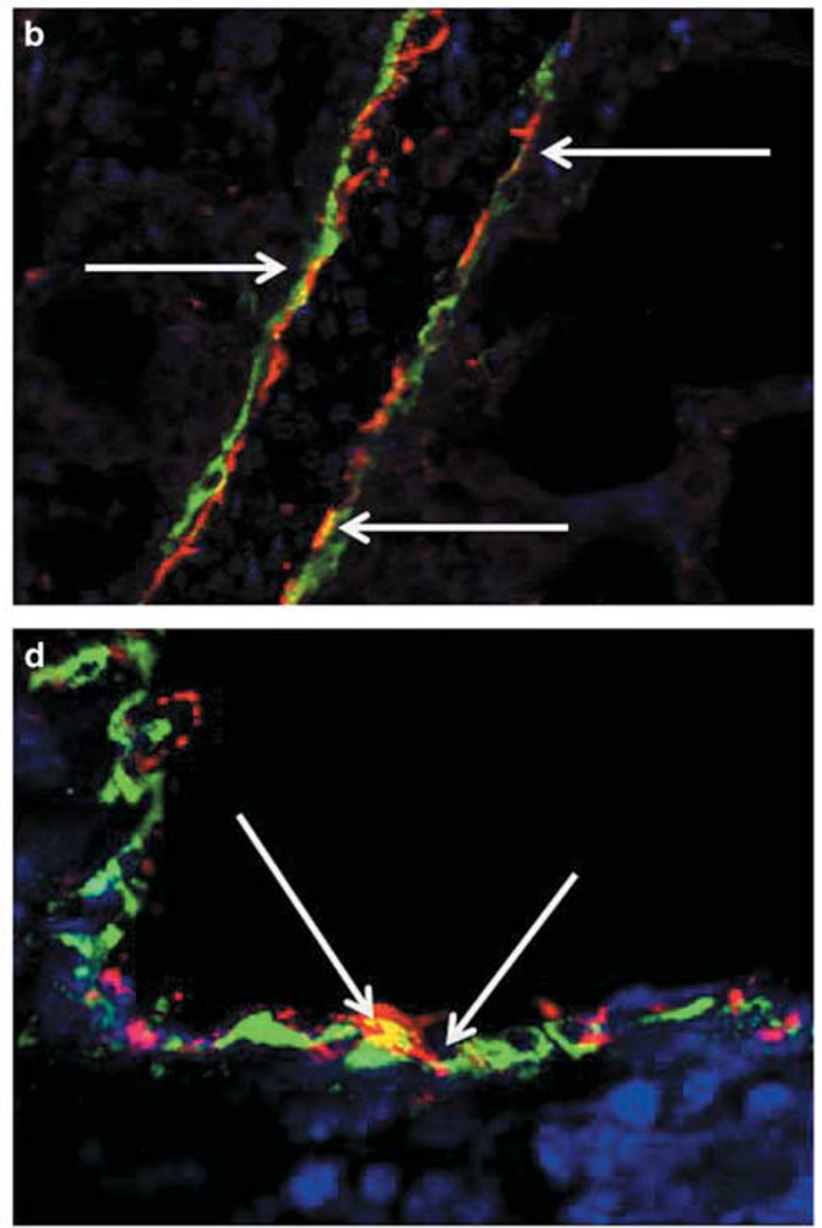

Figure 9 Immunohistology of endothelial cells in the lungs isolated from tamoxifen-injected TBRI ${ }^{\text {ca }}$-Cdh5-Cre transgenic mice. Confocal microscopic staining for vWF (red) and $\alpha$-SMA (green) in the lungs from TGF- $\beta^{\text {ca }} C d h 5-C r e$ control transgenic male mice (a and $\mathbf{c}$ ) or tamoxifen-injected mice (b and d). DAPI was used for counterstaining of nuclei. Magnification: $\times 40$ in panels (a and $\mathbf{b}$ ); $\times 60$ in panels (c and d). Endothelial cells expressing vWF (red) are seen lining the large and small vessels of the lung. Smooth muscle cells expressing $a$-SMA (green) are seen only in the vessel medial layer in the control samples ( $\mathbf{a}$ and $\mathbf{c}$ ) but $a$-SMA expressing myofibroblasts are present in the endothelial layer of the tamoxifen-injected mice (b and $\mathbf{d})$. Cells costaining for VWF and $a$-SMA (yellow; white arrows) are present in the endothelial layer of small vessels of the tamoxifen-treated animals (b and $\mathbf{d}$ ). No cells co-staining for VWF and $a$-SMA were found in the lungs from control mice (a and $\mathbf{c}$ ).

treated mice compared with the control mice (Figure 5). Gene expression studies of the skin and lung demonstrated marked upregulation of genes encoding several extracellular matrix components, including Col1a1, Col3a1, Col4a1, and Fn1, compared with control animals (Figure 6). Similarly, the expression of genes associated with myofibroblast transdifferentiation and activation displayed marked upregulation of Acta2, Fn-Eda, and Comp in the skin and lungs of tamoxifentreated animals (Figure 7). Upregulation of the TGF- $\beta$ regulated mesenchymal cell-specific transcription factors Snai1, Snai2, Twist, and Mrtfa was also found in TBRI ${ }^{\mathrm{ca}}{ }_{-}$ Cdh5-Cre mice (Figure 8). Immunohistochemical staining of the lungs of tamoxifen-injected mice for $\alpha$-SMA and the endothelial cell-specific vWF revealed numerous $\alpha$-SMApositive myofibroblasts both surrounding the blood vessels as well as distributed throughout the parenchyma compared with control mice (not shown). Strikingly, numerous cells displaying colocalized expression of mesenchymal and endothelial cell-specific markers were present in small vessels of tamoxifen-injected animals that were not observed in the lungs from control animals (Figure 9). These observations indicate that one source of the activated myofibroblasts may be the triggering of EndoMT in endothelial cells by the constitutive TGF- $\beta$ signaling as depicted in Figure 10. EndoMT, a complex biological process in which endothelial cells progressively lose expression of endothelial cell-specific phenotype while simultaneously acquiring the expression of mesenchymal-specific phenotype has been proposed as a potential source of activated myofibroblasts during the fibroproliferative process. ${ }^{39,40}$ Signaling through the TGF- $\beta$ receptor mediated by Smad2/3 translocation to the nucleus results in the upregulation of genes involved in synthesis of matrix components, genes involved in myofibroblast differentiation, and other TGF- $\beta$-regulated transcription factors. Of 


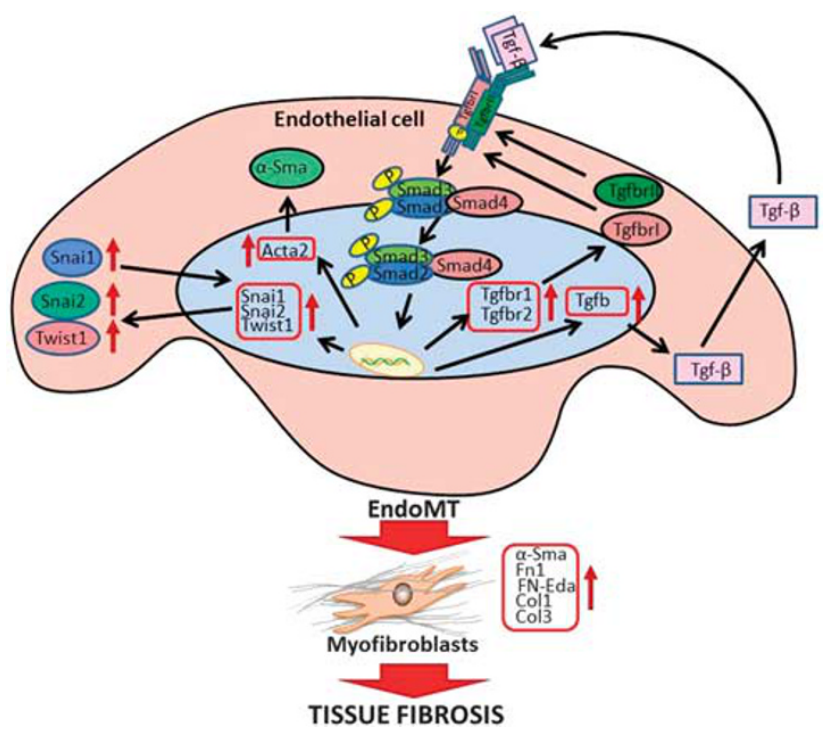

Figure 10 Diagrammatic representation of constitutively activated TGF- $\beta$ signaling-mediated tissue fibrosis. Schematic diagram representing signaling pathway initiated by constitutive activation of signaling through the TBRI. The constitutively active TBRI mediates the phosphorylation of Smad2/3 that along with Smad4 then translocates to the nucleus where it binds to gene promoters and mediates the increased expression of TGF$\beta$-regulated transcription factors such as Snai1, Snai2 and Twist as well as the TGF- $\beta$ receptors I and II. This induces an autocrine loop resulting in increased TGF- $\beta$ expression and signaling. One consequence of this is the induction of endothelial-to-mesenchymal transition (EndoMT), resulting in increased numbers of activated myofibroblasts. Activated myofibroblasts are responsible for increased expression and production of the fibrillar type I and III collagens and other extracellular matrix components such as Fn-1 and Fn-Eda that contribute to progressive tissue fibrosis.

remarkable importance are the observations that activation of this pathway also results in the increased expression of genes encoding the two TGF- $\beta$ receptors and, therefore, would induce the establishment of a highly efficient autocrine loop leading to a progressive and uncontrolled fibrotic process (Figure 10). This autocrine loop would be expected to result in the persistent stimulation of EndoMT and in the transdifferentiation of endothelial cells into activated myofibroblasts that can then engage in the progressive exaggerated production of matrix components that leads to tissue fibrosis as described previously. ${ }^{39,40}$

In conclusion, we report here the development of a novel transgenic mouse strain characterized by the constitutive activation of TGF- $\beta$ signaling in cells of endothelial origin that can be induced postnatally upon injection of $4-\mathrm{OH}-$ tamoxifen. Upon activation of the transgene, these mice develop profound fibrosis not only in multiple tissues, particularly the skin and lung, but also in the liver, heart and kidney, and remarkably, they also display prominent fibrotic changes in the small- and medium-sized vessels of these organs. These histopathological alterations display remarkable similarities to the fibrotic lesions and the fibroproliferative vasculopathy that are characteristic of SSc.
As such, the transgenic mouse strain generated here will provide a valuable resource for investigating the role of endothelial cell activation and the effect of constitutive endothelial cell-specific TGF- $\beta$ signaling in the pathogenesis of SSc-associated tissue fibrotic and vascular alterations. These mice will be a valuable model to study experimentally the contribution of the unique and cell-specific functions of endothelial cells toward the complex fibroproliferative process involved in SSc pathogenesis and to evaluate the efficacy of therapeutic agents designed to halt or ameliorate the fibrotic process in SSc and in other human systemic and organ-specific fibrotic diseases.

\section{ACKNOWLEDGMENTS}

This work was supported by an NIH grant AR 19616 to SAJ. We thank the expert assistance of Alana Pagano in the preparation of the manuscript.

\section{AUTHOR CONTRIBUTIONS}

Design of the study and manuscript preparation by PJW and SAJ. Data acquisition by PJW, KRC, FAM, and SP-V. Analysis of data by PJW and SAJ. Final manuscript prepared, revised, and approved by PJW and SAJ.

\section{DISCLOSURE/CONFLICT OF INTEREST}

The authors declare no conflict of interest.

1. Varga J, Abraham D. Systemic sclerosis: a prototypic multisystem fibrotic disorder. J Clin Invest 2007;117:557-567.

2. Gabrielli A, Avvedimento EV, Krieg T. Scleroderma. N Engl J Med 2009;360:1989-2003.

3. McCray CJ, Mayes MD. Update on systemic sclerosis. Curr Allergy Asthma Rep 2015;15:25.

4. Wynn TA, Ramalingam TR. Mechanisms of fibrosis: therapeutic translation for fibrotic disease. Nat Med 2012;18:1028-1040.

5. Wei J, Bhattacharyya S, Tourtellotte WG, et al. Fibrosis in systemic sclerosis: emerging concepts and implications for targeted therapy. Autoimmun Rev 2011;10:267-275.

6. Pattanaik D, Brown M, Postlethwaite AE. Pathogenesis of systemic sclerosis. Front Immunol 2015;6:272.

7. Stern EP, Denton CP. The pathogenesis of systemic sclerosis. Rheum Dis Clin North Am 2015;41:367-382.

8. Campbell RM, LeRoy EC. Pathogenesis of systemic sclerosis: a vascular hypothesis. Semin Arthritis Rheum 1975;4:351-368.

9. LeRoy EC. Systemic sclerosis. A vascular perspective. Rheum Dis Clin North Am 1996;22:675-694.

10. Fleming JN, Schwartz SM. The pathology of scleroderma vascular disease. Rheum Dis Clin North Am 2008;34:41-55.

11. Kahaleh B. Vascular disease in scleroderma: mechanisms of vascular injury. Rheum Dis Clin North Am 2008;34:57-71.

12. Trojanowska M. Cellular and molecular aspects of vascular dysfunction in systemic sclerosis. Nat Rev Rheumatol 2010;6:453-460.

13. Matucci-Cerinic M, Kahaleh B, Wigley FM. Review: evidence that systemic sclerosis is a vascular disease. Arthritis Rheum 2013;65: 1953-1962.

14. Altorok N, Wang $\mathrm{Y}$, Kahaleh B. Endothelial dysfunction in systemic sclerosis. Curr Opin Rheumatol 2014;26:615-620.

15. Pattanaik D, Brown M, Postlethwaite AE. Vascular involvement in systemic sclerosis (scleroderma). J Inflamm Res 2011;4:105-125.

16. Van Linthout S, Miteva K, Tschope C. Crosstalk between fibroblasts and inflammatory cells. Carciovasc Res 2014;102:258-269.

17. Hassoun PM, Mouthon L, Barbera JA, et al. Inflammation, growth factors, and pulmonary vascular remodeling. J Am Coll Cardiol 2009;54 (1 Suppl):S10-S19.

18. Chizzolini C, Brembilla NC, Montanari E, et al. Fibrosis and immune dysregulation in systemic sclerosis. Autoimmun Rev 2011;10:276-281.

19. Hinz B, Phan SH, Thannickal VJ, et al. The myofibroblast: one function, multiple origins. Am J Pathol 2007;170:1807-1816. 
20. McAnulty RJ. Fibroblasts and myofibroblasts: their source, function and role in disease. Int J Biochem Cell Biol 2007;39:666-671.

21. Hinz B, Phan SH, Thannickal VJ, et al. Recent developments in myofibroblast biology: paradigms for connective tissue remodeling. Am J Pathol 2012;180:1340-1355.

22. Kramann R, DiRocco DP, Humphreys BD. Understanding the origin, activation and regulation of matrix-producing myofibroblasts for treatment in fibrotic disease. J Pathol 2013;231:273-289.

23. Sporn $M B$, Roberts $A B$, Wakefield $L M$, et al. Transforming growth factor-beta: biological function and chemical structure. Science 1986;233:532-534.

24. Varga J, Rosenbloom J, Jimenez SA. Transforming growth factor beta (TGF beta) causes a persistent increase in steady-state amounts of type I and type III collagen and fibronectin mRNAs in normal human dermal fibroblasts. Biochem J 1987;247:597-604.

25. Lafyatis R. Transforming growth factor $\beta$-at the centre of systemic sclerosis. Nat Rev Rheumatol 2014;10:706-719.

26. Varga J, Whitefield ML. Transforming growth factor-beta in systemic sclerosis (scleroderma). Front Biosci 2009;1:226-235.

27. Denton CP, Abraham DJ. Transforming growth factor-beta and connective tissue growth factor: key cytokines in scleroderma pathogenesis. Curr Opin Rheumatol 2001;13:505-511.

28. Kawakami T, Ihn H, Xu W, et al. Increased expression of TGF-beta receptors by scleroderma fibroblasts: evidence for contribution of autocrine TGF-beta signaling to scleroderma phenotype. J Invest Dermatol 1998;110:47-51.

29. Pannu J, Gore-Hyer E, Yamanaka M, et al. An increased transforming growth factor beta receptor type l:type II ratio contributes to elevated collagen protein synthesis that is resistant to inhibition via a kinasedeficient transforming growth factor beta receptor type $\|$ in scleroderma. Arthritis Rheum 2004;50:1566-1577.

30. Wermuth PJ, Li Z, Mendoza FA, et al. Stimulation of transforming growth factor- $\beta 1$-induced endothelial-to-mesenchymal transtition and tissue fibrosis by endothelin-1 (ET-1): a novel profibrotic effect of ET-1. PLoS ONE 2016;11:e0161988.

31. Sonnylal $S$, Denton $C P$, Zheng $B$, et al. Postnatal induction of transforming growth factor $\beta$ signaling in fibroblasts of mice recapitulates clinical, histologic, and biochemical features of scleroderma. Arthritis Rheum 2007;56:334-344.

32. Alva JA, Zovein AC, Monvoisin A, et al. VE-Cadherin-Cre-recombinase transgenic mouse: a tool for lineage analysis and gene deletion in endothelial cells. Dev Dyn 2006;235:759-767.

33. Monvoisin A, Alva JA, Hofmann JJ, et al. VE-cadherin-CreERT2 transgenic mouse: a model for inducible recombination in the endothelium. Dev Dyn 2006;235:3413-3422.

34. Del Galdo F, Sotgia F, de Almeida CJ, et al. Decreased expression of caveolin 1 in patients with systemic sclerosis: crucial role in the pathogenesis of tissue fibrosis. Arthritis Rheum 2008;58:2854-2865.

35. Stegemann H, Stalder K. Determination of hydroxyproline. Clin Chim Acta 1967;18:267-273.

36. Edwards CA, O'Brien Jr. WD . Modified assay for determination of hydroxyproline in a tissue hydrolysate. Clin Chim Acta 1980;104:161-167.

37. Wermuth PJ, Del Galdo F, Jimenez SA. Induction of the expression of profibrotic cytokines and growth factors in normal human peripheral blood monocytes by gadolinium contrast agents. Arthritis Rheum 2009;60:1508-1518.

38. Mendoza FA, Piera-Velazquez S, Farber JL, et al. Endothelial cells expressing endothelial and mesenchymal cell gene products in lung tissue from patients with systemic sclerosis-associated interstitial lung disease. Arthritis Rheumatol 2016;68:210-217.

39. Piera-Velazquez S, Li Z, Jimenez SA. Role of endothelial-mesenchymal transition (EndoMT) in the pathogenesis of fibrotic disorders. Am J Pathol 2011;179:1074-1084.

40. Jimenez SA. Role of endothelial to mesenchymal transition in the pathogenesis of the vascular alterations in systemic sclerosis. ISRN Rheumatol 2013;2013:835948. 